\title{
Message from Professor Budi Wiweko
}

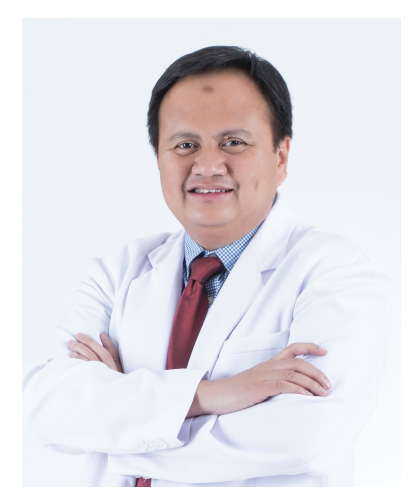

It has been 40 years since IVF was first founded by Professor Patrick Steptoe and Robert Edward with more than 8 million babies being born into the world using this technology. Outstanding achievements in assisted reproductive technology have been helping infertile couples to attain their dreams and become parents. However, despite the advancement of our science, there are still many grey areas left unanswered.

"We are at the end of the beginning, not the beginning of the end," as quoted by Patrick Steptoe approximately four decades ago. This futuristic statement can be explained by our current situation which is supported by the cutting edge of reproductive technology and the development of precision medicine. However, the success rate of in vitro fertilization is still very limited. Many areas relating to oocytes, sperms, embryos, and endometrial receptivity are still mysteries.

A decade of Asia Pacific Initiative on Reproduction (ASPIRE) was dedicated to improve the quality of assisted reproductive technology. To bridge the gap of ART in our region, we are really focused on increasing the competencies of all IVF providers in the Asia Pacific region. After successfully launching the ASPIRE master class four years ago, we are currently concentrating on establishing special interest groups (SIGs) and our own official journal Fertility \& Reproduction ( $F \& R$ ).

$F \& R$ will review all research and innovation in the field of assisted reproductive technology and consider it for publication. With the support of some great names on the editorial board and world-renowned scientists in the Asia Pacific region, we believe that $F \& R$ will become one of the most reputable scientific journals in the field.

I would like to thank all editorial board members who have been working very hard for this inaugural issue of the Journal.

We welcome all IVF experts to submit your excellent work and join our journal to bridge the gap of ART in Asia Pacific.

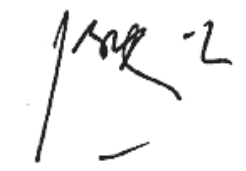

Professor Budi Wiweko President of ASPIRE

() 2019 by the Asia Pacific Initiative on Reproduction (ASPIRE) and World Scientific Publishing Co. Pte. Ltd. 2 Open Access article under the CC BY-NC-ND license (http://creativecommons.org/licenses/by-nc-nd/4.0/). 